\title{
Prospects and Challenges of Dynamic Bilingual Education in the Light of Pakistan's Language Policy
}

\author{
Ameer Ali \\ Institute of English Language and Literature, University of Sindh, Jamshoro, Pakistan
}

\begin{abstract}
This research investigates challenges and prospects of the dynamic, bilingual education in the light of Pakistan's language policy. It guides language policymakers to adopt the dynamic, bilingual policy in Pakistan's education system. However, the researcher revealed that most of the participants willingly favored and practiced the dynamic model of bilingual instruction, but there is no formal policy guide for them. The employment of this education model is valid and feasible in both theory and practice. Besides, readers and policymakers through this research paper would come to know that the dynamic, bilingual education improves students' socio-cognitive, linguistic performance and functional biliteracy through translanguaging and multimodalities. The issue of monoglossic separation of languages in Pakistan is yet to be solved. Furthermore, the researcher used qualitative, empirical methodology to do analysis and employed open-ended questionnaires to collect data. The researcher used purposive sampling to collect data from sixteen respondents. Additionally, findings show that the subtractive language policy, linguistic politics, the power elite's monolingualism, parents' obsession with English, and students' negative attitudes are challenges to the dynamic, bilingual education. In contrast, Pakistan's multi-lingual reality along with translingual practices, the use of multimodalities, students' multi-lingual repertoire, functional biliteracy, and transcultural interaction are some of the prospects of the dynamic, bilingual education policy in Pakistan. Thus, there are both challenges and prospects of the dynamic, bilingual education policy in Pakistan.
\end{abstract}

Key words: $\quad$ Bilingual Education, Dynamic, Functional Biliteracy.

\section{Introduction}

The current research paper draws its motivation from the practical benefits offered by the dynamic, bilingual education in a multilingual society. Bilingual mode of instruction will be beneficial for Pakistan (Raja, 2014). Furthermore, research questions of this research work are highly significant as they seek to address the hopes and prospects of bilingual education in Pakistan. Besides, this research will convince policy makers to introduce dynamic, bilingual medium of instruction in educational institutions. Consequently, the bilingual policy when imposed would enhance socio-cognitive, linguistic performance and functional biliteracy of students through multimodalities and translanguaging. The use of multimodalities in the classroom, such as visuals, graphics, sounds, and texts will enhance students' literacy. Besides, the dynamic model of education through translanguaging will build up the students' multilingual literacy. Thus, through multimodalities and multi-languages, the dynamic system of education will bring about the functional biliteracy/multiliteracy among students. Similarly, the educational, social gaps between lower and upper class will be much reduced through employment of dynamic, bilingual education policy. In the realms of Educational Linguistics and Applied Linguistics, many researchers will look to this research paper to carry out a classroom-based research in bilingual education which unfortunately lacks in Pakistan (Jabeen, 2010).

The models of subtractive bilingualism, additive bilingualism, and recursive bilingualism are insufficient in reflecting the complex bilingual competence and needs required in some societies of the current century (Garcia, 2009 pg. 180-181). In the twenty first century, a more heteroglossic conception of bilingual education is needed that easily adjusts with the regular changes (Garcia, 2009 pg. 180-181). Bilingual education is not linear but dynamic, because it develops and functions in different contexts. For the dynamic model of bilingual education, the language categories, such as L1 and L2 are no longer useful. The rapid pace of globalization is defying traditional categories (Garcia, 2009 pg. 180-181). The dynamic model of education involves multiple language practices and it keeps adjusting to the multilingual, multimodal terrain of the communicative act (Garcia, $2009 \mathrm{pg}$. 180-181). Similarly, Pakistan also needs the dynamic, bilingual education system which enables teaching and learning on the different planes of multimodalities, such as visuals, print, text, and so on. Additionally, it also dynamically facilitates the individual learners to engage in multilingual, complex communicative acts which are not allowed by linear models of bilingual education (Garcia, 2009 pg. 180-181). Thus, to make teaching effective through multimodalities and 


\section{Yinternational Research Journal}

p-ISSN 2202-2821 e-ISSN 1839-6518 (Australian ISSN Agency)

multi-languages, Pakistan needs the dynamic, bilingual education system.

Language policymakers have been neglecting bilingual education in Pakistan since 1947. According to many researchers (Channa, et. al, 2016), the policy of subtractive, bilingual education, which sidelines local/mother languages, is badly impacting socio-cognitive, linguistic performance of students in Pakistan. There have been some effective attempts to promote the linear models of bilingual education. These models of bilingual education either strictly separate or flexibly converge the management of English or Urdu as a medium of instruction. While Pakistan's language planning and policies demote dynamic, bilingual education in which multimodal and multi-lingual instructions are promoted. This lack of dynamic, bilingual education has been shown to have negative associations with students' socio-cognitive, linguistic performance, functional biliteracy and social cohesion and is becoming an increasing concern for Pakistan's education sector. When students cannot get education through multimodalities and translanguaging, they are likely to become more excluded overtime, leading to an erosion of linguistic diversity and perpetuation of socio-economic inequality in Pakistan. Addressing this problem through the dynamic, bilingual education will bring about both educational and political benefits for Pakistan.

\section{Research Question:}

The research will address the following question:

- How does the lack of the dynamic, bilingual education influence the indigenous languages of Pakistan?

\section{Literature Review}

There are no explicitly stated language or language-ineducation policies in multi-lingual society of Pakistan (Mahboob \& Jain, 2017). Language policy in Pakistan suffers ambiguity of purpose. Language policymakers are still in the process of 'consultation' without any attempt at introduction of bilingual education policy (Federal Ministry of Education, 2009). Although the Federal Ministry of Education and Professional Training (2009) formulated a policy, but it is quite vague in its statements. This policy indeed gives provinces authority to choose medium of instruction, but it offers no recommendations which endorse dynamic, bilingual education. It merely emphasizes the use of a local language at primary level, while students are to get education through English as medium of instruction at higher levels (Federal Ministry of Education and Professional Training, 2009). Therefore, this policy has perpetuated an educational gap between students of government and elite schools (Channa et. al. 2016). Quite recently, the Federal Ministry of Education
Vol. 10 No. 022020

82801002202005

and Professional Training (2020) has introduced a new language policy, but it also fails to address the multilingual reality of Pakistan.

Ahmar Mahboob and Rashi Jain (2017) cogently argue that over seventy percent (70\%) private schools use English as the only medium of instruction in Pakistan, while majority of government schools use either Urdu or another local language as a medium of instruction. Besides, the higher education institutions use English as a medium of instruction (Mahboob \& Jain, 2017). This scenario indeed indicates language policy misalignment among private schools, government schools, and the institutions of higher education (Mahboob \& Jain, 2017). In the existing language ecology, the English only policy entails reductionist impacts on the local languages and it also brings about socio-economic disparities between "haves" and "have-nots" (Manan et. al. 2016). Furthermore, the lack of clear, uniform language policy has had a harmful impact on learning (Habib, 2013).

Much like Habib (2013), Rafia Hasan (1981) also advocates clearly defined, uniform bilingual policy of education as it improves students learning processes. In her research, she found out that bilinguals suffered in lower classes, but their performance significantly improved as they climbed much higher classes (Hassan 1981). Hasan (1981) tested the students who got education through bilingual linear models which strictly separate languages. However, the students who get education through the dynamic models of bilingual education tend to perform much better than the monoglots. Similarly, Sunaina Asher (2019) revealed that bilingual education in which mother tongue (L1) is included as a medium of instruction improves socio-cognitive performance of students. Moreover, it will also raise the socio-economic status of people who use it (Asher, 2019). The use of home language and a language of much wider communication as medium of instructions in fact ensures better performance and success for students (Mahon et. al, 2003).

In contrast, most parents in Pakistan prefer English only policy at all levels of education (Habib, 2013). But this monolingual approach towards teaching and learning backfires (Manan, et al, 2016). The lack of qualified English teachers, socio-cultural dynamics, ineffective pedagogies, and other weaknesses bring about the failure of the policy (Manan, et. al, 2016). To compensate for this failure, most of the teachers often make use of code-switching (Gulzar, 2010; Raja, 2014). Although code-switching makes teaching highly effective (Tariq, et. al, 2013), but there is no established pattern to determine the percentage of the use of code-switching and L1 in a bilingual classroom (Gulzar \& Qadir, 2010). Thus, parents' attitude and lack of policy pose challenges to the 


\section{Yinternational Research Journal}

p-ISSN 2202-2821 e-ISSN 1839-6518 (Australian ISSN Agency)

dynamic, bilingual education that encourages transcultural languaging.

In addition to parents' attitude, politicians' use of language as an instrument to suppress or surpass a linguistic group has also posed a very serious challenge to dynamic, bilingual education policy in Pakistan (Channa, et. al. 2016). Language decisions inspired ethno-linguistic conflicts among minority groups as these were pre-occupied with Urdu and the spirit of Islam (Channa, et. al, 2016). In Pakistan where six major and fiftyeight minor languages are used (Rahman, 2004), linguistic variety usually ends up as a tactical tool in politicians' hands. Furthermore, policy makers in service of politicians have always tried to impose a dominant language through schools, a reckless act which always backfires (Global Education Monitoring Report, 2016). Bengali and Urdu controversy and Urdu and Sindhi controversy are two, convincing examples of politically inspired language policies that have ended up as horrible debacles.

Pakistan has a linguistic variety of 0.802 on Greenberg Index (Lewis et al. 2016). Supporting monolingual policies in such a multi-lingual society would indeed always pave the way for ethnolinguistic conflicts. This indeed has been the case for decades. The policy makers will have to look for a much more feasible language policy that guarantees the linguistic rights of all the ethnic groups. Although Pakistan's language policy has always brought about problems, it is through the adoption of the dynamic, bilingual policy that functional biliteracy, transcultural interaction and multilingual and multimodal education in Pakistan can be realized; thus, Pakistan's linguistic, educational, and social problems will be solved. Moreover, this model views bilingual education as social practices of individuals with translanguaging at its core (Heller, 2007). Through translanguaging, this model can lead policymakers to give up a linear viewpoint and employ a more heteroglossic lens, which would entail a fuller vision of the range of language practices and experiences that bilinguals bring (Garcia, 2009 pg. 180-181). Finally, the current research paper is an attempt at showing ground realities that are quite favorable for the dynamic bilingual, educational policy, and thereby it would cogently persuade the policy makers to view the bilingual instruction policy in a much more positive manner.

\section{Research Methodology}

The current research is empirical as it makes use of qualitative questionnaires as a method of data collection. As the aim of this research is to address a practical problem of language policy, the use of open-ended questionnaire is quite helpful. To make this research much more effective, the researcher has made sure to adhere to the use of questionnaire
Vol. 10 No. 022020

82801002202005

protocol (Creswell, 2012 quoted in Quad, 2016). It is a standard way of getting in-depth views of participants without additional probing (Creswell, 2012 quoted in Quad, 2016). Besides, this design is very advantageous when there is a comprehensive list of questions because it helps targeting the phenomenon or experience that the researcher is focusing. Hence, it is both philosophically and ethically feasible to employ this research design.

\section{A. Method of data collection}

The researcher employed open-ended questionnaire to collect data. Through purposive sampling, the researcher politely convinced teachers, M.Phil., and BS students from different areas of Pakistan to take part in the research. Sixteen respondents, both men and women, were included as participants in the research through purposive sampling. The age of the respondents ranged from 25 to 34 . Moreover, nine questions were sent through email and WhatsApp to the respondents due Covid-19. Due to privacy, the names of respondents were replaced with numerals. Through the questionnaire, the researcher managed to get mature, learned, and in-depth feedback related to the prospects and challenges of the dynamic, bilingual education in Pakistan. Hence, the use of the qualitative design helped researcher in achieving objectives.

\section{B. Method of Analysis}

After the data collection, the researcher conducted qualitative, thematic analysis. It involved coding all the data before identifying and reviewing two key themes. Later, each theme was analyzed to gain an understanding of the participants' perceptions and motivations related to the topic.

\section{IV.Findings}

In this segment, the thematic analysis of data is carried out based upon the headings: Challenges of Bilingual Education in the Light of Pakistan's Language Policy and Prospects of Bilingual Education in the Light of Pakistan's Language Policy.

\section{A. Challenges to Dynamic, Bilingual Education in Light of Pakistan's Language Policy}

The system of bilingual education faces pedagogical, social, political, and cultural challenges as there is no support for it in Pakistan's language policy. One of the participants when asked about the impacts of not adopting the dynamic, bilingual education policy and thereby undertaking no such related training made the following comment:

"Local languages of Baluchistan are neglected in formal institutions. Both parents and administration support English 


\section{Yinternational Research Journal}

p-ISSN 2202-2821 e-ISSN 1839-6518 (Australian ISSN Agency)

only policy in private schools. In government schools, Urdu has got full support and English has been supported partially. However, local languages do not have any space in schools, colleges, and universities. Even, the teacher of my niece has prescribed her to communicate in Urdu with her mom at home. So, lack of concern for the dynamic, bilingual education is a threat to indigenous languages of Baluchistan. Local languages face serious survival issues. Recently, an effort was made to teach local languages as additional subjects in primary schools. However, the policy has not been implemented though textbooks of languages have been made. It shows a lack of appreciation from school administration and educational department of Baluchistan" (Participant 1).

Speaking in Baluchistan's context, one of the provinces in Pakistan, the participant (1) convincingly shows that school is the first formal institution where monolingual policy of education is marginalizing the local languages. Furthermore, his response also illustrates that the lack of dynamic, bilingual education is also threatening functional biliteracy, because the participant's niece (her mother tongue is Hazaragi) has been asked by her teacher to speak Urdu even when she is at home with her family. He also emphasizes the fact of preserving the indigenous languages through translanguaging and multimodal instructions and practices. Similarly, describing students' and teachers' attitudes towards the dynamic, bilingual education, another participant says:

"Parents do not seem to appreciate the dynamic, bilingual education. It is the result of a discourse that English is necessary, and students can learn English only if English is employed as a sole medium of instruction. Parents prefer English medium schools without knowing the implications and consequences. Besides, our approach towards languages has persuaded the parents that local languages are not important. They consider English as a gatekeeper language. We find ethnolinguistic dilemma in the approach of students and parents. Now, a discourse is needed that local languages are important in education. Linguists and policy makers have to persuade the parents that local languages should be taught in schools and students should learn English and Urdu in a truly dynamic, bilingual education system" (Participant 2).

In the above statement, the participant (2) sets forth cogently that Pakistan's policymakers, students, and their parents are still mentally colonized. The process of decolonizing their minds is yet to take place. Most of them he means to imply support monolingual medium of instruction through English without knowing the repercussions the policy would entail for the indigenous languages. The English only policy has full support of parents as stated by Habib (2013). In the same vein the third respondent goes on:
Vol. 10 No. 022020

82801002202005

"There are many hurdles in implementing the dynamic, bilingual education. the Anglicized class of Pakistan never supports the dynamic, bilingual education. We do not find the quest for the bilingual education though current education system does not produce scientists, philosophers, researchers, and creative thinkers. There is a lack of concern towards the bilingual education both in policy makers and people. We find the supporters of English only policy who are in power and they never want to lose their status and privilege. We also find some businessmen in education sector who are also against the dynamic, bilingual language policy, because their businesses relate to promotion of English. We also find a lack of academic expertise in policy makers who are uninterested in language and education. There are some of the serious challenges and issues that the bilingual education is currently facing all over Pakistan".

The participant adds that Pakistan's elite class and inexperienced policy makers are very serious challenges to the dynamic, bilingual education system because their interests lie with English only policy. This shows how the power elite's economic interests always overcome interests of the common people who fail to achieve quality education through the bilingual instruction. Moreover, this monolingual policy does not address the complex, linguistic repertoire shared by the language learners. This English- only policy, inspired by the monoglossic ideology, treats languages as separate systems. Thus, it is a challenge to the policy of the dynamic, bilingual education that endorses the multilingual and multimodal realities of discourse. The participant also imputes the educational failures with the monolingual education policy.

This situation has indeed engendered a certain degree of pessimism among the proponents of the dynamic, bilingual education system. Thus, a participant (4) laments:

"I don't think that there are any prospects of the dynamic, bilingual education, because our local languages haven't been so strong as a result of foreign language dominancy" (Participant 4).

He believes that the linguistic hegemony of the foreign language that is of course English is so strong that people hardly feel any need at all to practice local languages. English language enjoys so much great power in Pakistan that it has become almost impossible to resist it and thereby difficult to create some space for teaching through translanguaging and multimodalities. Furthermore, the participants most of whom are either teachers or language scholars were asked to express their attitude towards monolingual language policy and how they preferred to conduct their class made some revealing remarks. The participant (5) expresses her views: 


\section{Yinternational Research Journal}

p-ISSN 2202-2821 e-ISSN 1839-6518 (Australian ISSN Agency)

"In Pakistan, educational institutions mostly adopt a monolingual way to teach their students, either in English, Sindhi, Urdu or the preferred mother tongue of the very area. In our area, the situation goes on in the same direction. In our area, if students belong to a multilingual background, we teach them through Urdu language, as it can be understood by every student" (Participant 3).

The participant (5) says that she prefers to use a local language to teach her students. But when she encounters students speaking different languages, she likes to use Urdu as a medium of instruction instead of translanguaging to make understanding a topic much easier. This scenario also brings us to the painful fact that the monolingual education system is a norm across Pakistan due to the flawed language policies. Though students must get education in their local language or mother tongue, depriving the students of a language of much wider communication, such as English also creates educational gaps among students. Speaking on the lack of the dynamic, bilingual education policy, there is yet another participant (6) who continues:

“...it can lead other languages to get vanished because of their minimum usage, it can deviate students from learning other cultures, it can build a social psyche of learning in a particular language and not giving importance to other local languages and so on" (Participant 6).

This monolingual education policy in which either English or Urdu is used as a medium of instruction has had detrimental effects on learners' psyche. Consequently, the learners have come to believe that English and Urdu are languages of education, while the vernaculars are the languages of uneducated people and thereby, they have no institutional, educational value. Besides, this is also a result of Pakistan's flawed language policy. To uplift the status of local languages, policy makers will have to devise such mechanisms as they guarantee the imposition and use of the dynamic, bilingual medium of instruction in Pakistan's educational institutions. Besides, the lack of transcultural interaction and learning also bring about linguistic decay. Hence, the participant (7) warns against the gruesome consequences if the dynamic, bilingual policy is not adopted as soon as possible:

"The Dynamic, bilingual education in its true sense has never been appreciated. Local languages are not given their due rights to be taught, promoted, and disseminated. This treatment causes the death and decay of the local languages" (Participant 7).

The participant's views indicate the inevitable outcome that is highly undesirable. If the dynamic, bilingual instruction policy is not adopted, many local languages in Pakistan will become
Vol. 10 No. 022020

82801002202005

extinct thereby mitigating the country's rich linguistic diversity. Only through the dynamic, bilingual education policies which develop multilingual repertoire, this process can be reversed. Once the dynamic, bilingual education becomes a norm in the country's educational institutions, the variety of traditions, narratives, cultures, and of course languages will make it quite rich with the wealth of heritage and intellect. But unfortunately, the challenges posed by the monolingual policies persist and thus haunt the country. Furthermore, the multilingual richness becomes a challenging task for the language policymakers to deal with. The participant (8) concludes:

"Since Pakistan is a multi-lingual country where ranges of ethnic groups exist, it is hard for the government to manage teaching and promoting of these local languages, and giving one language priority means disregarding other languages which creates a destabilizing atmosphere in the country" (Participant 8).

It becomes difficult to devise an-all-inclusive language policy for a country that enjoys a linguistic variety of 0.802 on Greenberg Index (Lewis et al, 2016). But it does not naturally imply that the monolingual policy is a solution to the country's linguistic problems. The policymakers will have to involve all the stakeholders and take into consideration the multi-lingual variety. Afterwards, they must develop a comprehensive plan that seeks to mainstream the dynamic, bilingual education that enables learners to translanguage in local languages along with language of much wider communication. Thus, the challenges posed by the status quo language policies can be effectively countered.

\section{B. Prospects of Dynamic, Bilingual Education in Light of Pakistan's Language Policy}

In contrast to the challenges, there are in fact many promising factors in Pakistan's society which indicate that one day policymakers will find it inevitable to devise and impose the dynamic, bilingual education policy. The country's multilingual variety is one of these factors which sets forth prospects for the dynamic, bilingual medium of instruction. Commenting on the prospects of the dynamic, bilingual education in Pakistan, the participant (8) argues:

"Pakistan is a multi-cultural and multi-lingual country. The dynamic, bilingual education policy is the need of time. It is natural that a child who spends five years in learning his mother tongue cannot develop cognition and cannot learn properly in a foreign language. Both Urdu and English are foreign languages to someone whose L1 is other than Urdu. Urdu is the mother tongue of 7\% of Pakistanis. English or Urdu medium in school especially in primary section is a big 


\section{Yinternational Research Journal}

p-ISSN 2202-2821 e-ISSN 1839-6518 (Australian ISSN Agency)

hurdle for speakers of local languages. It promotes memorization and cramming among students. It also destroys the creativity of the students. I think it is the basic right of every human that he gets education in his mother tongue until and unless he is familiar with foreign languages. But to improve the quality of education, to make sure students show interest in education and to develop cognition of students properly, we need the dynamic, bilingual education where students' multilingual reality is appreciated" (Participant 8).

The participant (8) persuasively says that the multilingual reality would someday drive the country towards the dynamic, bilingual education policies. The monolingual policy is making it difficult for students to improve their sociocognitive performance and functional multiliteracy when the only exposure they have in their class is through either L1 or L2. Moreover, the participant also argues that it is a linguistic right of every child to get education through the dynamic, bilingual medium of instruction. He also tells that the Englishin-education policy is a form of monolingual policy that promotes nothing except cramming and memorization among students. The only solution, he argues, lies in adopting the dynamic, bilingual medium of instruction which appreciates the multilingual practices and multimodalities. While expressing his attitude towards the dynamic, bilingual education policy and its potential benefits, the participant (9) says:

"I want to teach bilingually using translanguaging as a strategy. Translanguaging with the help of visuals and sounds allows me to use language and local knowledge to students, benefit and since the students are already familiar with their language and culture, they will learn the concepts easily. They will participate and take interest. The dynamic, bilingual education will build the ability to think creatively. Students will no more practice memorization and cramming" (Participant 9).

He reveals that the dynamic, bilingual education is a solution to cramming and memorization. It makes learning much easier through multimodalities, such as texts, visuals, sounds, and graphics, for students who consequently engage themselves in transcultural, creative processes. It also enhances their interest and they start taking part in classroom activities. Furthermore, the participant says that he would make use of translanguaging as an effective strategy to uphold the known bilingual medium of instruction in his class. Besides, the participant (10) also criticizes the top down approach of policy makers and suggests a way forward:

"I support academia who are expert in language policy and language planning and conduct research in their field. They might persuade the people and authorities that the dynamic,
Vol. 10 No. 022020

82801002202005

bilingual education is the need of time. If they are given space and supported by government officials, they can change our education and language policy which will be in support of the indigenous languages. We should develop critical thinking through critical discourse analysis and postcolonialism among students who can question top-down approach and old policy of the English people. In this way, we might see a discourse in support of the local languages. Also, the state of Pakistan should support and endorse the multi-cultural and multi-lingual reality" (Participant 10).

Sharing his expert views, the participant suggests language policy makers to adopt a bottom-up approach rather than the colonial era top-down approach. The language researchers should further investigate the multi-lingual realities and thus come up with a very influential language policy which unfortunately does not exist now. Apart from raising critical consciousness of students, the stakeholders will have to construct local-languages-friendly discourse that will have to draw upon the benefits of the bilingual/multilingual translanguaging. Thus, the concerned authorities might be persuaded into adopting the dynamic, bilingual policy. In the same way, the participant (11) continues:

"The officials and policy makers have responsibility to work on implementing the dynamic, bilingual education policy. However, in many countries, the bilingual education policy has already been adopted. In Pakistan, educators and policymakers should bring out the dynamic, bilingual policies for the educational institutions" (Participant 11).

He emphasizes that it is now the responsibility of Pakistan's language policymakers to learn from other countries' successful experiences and thereby introduce the dynamic, bilingual education policy in Pakistan.

When the participants were asked about the reasons and importance of introducing the dynamic, bilingual education policy in Pakistan, the participant (12) gave a very convincing answer:

"The dynamic, bilingual education policy is very much important as it can promote the local languages too. Additionally, the bilingual education policy can make education easy for the students as bilingual courses can be designed in the local languages with the help of multimodal discourses and students can learn the concepts easily" (Participant 12).

He means to imply that the dynamic, bilingual education draws its importance from the very fact that it promotes the local languages through translanguaging and multimodalities. Besides, this educational policy also encourages the instructional use of the marginalized languages and thereby 


\section{Yinternational Research Jourma!}

p-ISSN 2202-2821 e-ISSN 1839-6518 (Australian ISSN Agency)

promoting the linguistic rights of all the ethno-linguistic groups. The participant also expresses the fact that bilingually designed curriculum makes it much easier for students to learn topics and thus improve their socio-cognitive, linguistic performance and functional biliteracy in an unprecedented way. Thus, it is through the dynamic, bilingual medium of instruction that learning, and teaching becomes much more effective.

Similarly, speaking on the need of imposing the dynamic, bilingual education in Pakistan, the participant (13) says in a revealing manner:

"Pakistan, a region of multi-languages and cultures, needs to build an education system and reform its policies which ensure teaching students in a translingual and multimodal way to enhance their social, cultural, and political wit. Thus, the dynamic, bilingual medium of instruction will be beneficial for Pakistan" (Participant 13).

She argues that the dynamic, bilingual education system is much more beneficial for Pakistan's society than any other monolingual system. Providing education bilingually, reduces social disparities between students of the upper class and the lower class. Moreover, this mode of instruction will also enrich cultural variety of Pakistani students. Additionally, by making learning much easier, the dynamic, bilingual medium of instruction will bring about transcultural interaction in students. Thus, she means to say that a multi-lingual society like Pakistan would benefit by the dynamic, bilingual medium of instruction. Like other participants, she is also much hopeful about the future of the dynamic, bilingual education in Pakistan:

"Every society gets changed, reformed, and improved with the passage of time. Policy makers need to think on all sides of the dynamic, bilingual education and its pros and cons. It has been observed widely that teaching bilingually improves the quality of education as compared to the monolingual medium of instruction. Therefore, I think policy makers will thoroughly look upon this problem and adopt the dynamic, bilingual education policy someday" (Participant 14).

The participant (14) cogently says that change is natural, therefore, Pakistan's flawed language policy will also conform to the changing needs of time. Furthermore, she says that the time is ripe and thus suggests policymakers to introduce the dynamic, bilingual education policy as it ensures the quality education for all through multi-languages and multimodalities. It is a serious problem that needs to be addressed instantly. Thus, she believes that one day the ground realities and experience will enable the language policy makers to look to
Vol. 10 No. 022020

82801002202005

the dynamic, bilingual education policy in educational interests of Pakistan.

The participant (15) confidently associates nations' progress with the dynamic, bilingual education policy:

"No nation ever on the planet earth has made progress while giving the least of attention to indigenous languages. It gives learner the confidence to learn faster and understand the subject and skills easily. It should be the primary goal of our educational policy to teach local languages in schools through the dynamic, bilingual education system" (Participant 15).

He emphasizes the generally accepted fact that the policy of the dynamic, bilingual education, which recognizes translanguaging (with emphasis on the indigenous languages) as medium of instruction will indeed entail Pakistan's progress. Teaching through the dynamic, bilingual medium of instruction creates well-educated members of society who always play a very vital role in their nation's development. Therefore, he suggests that it must be a primary goal of policymakers to devise a dynamic, bilingual education policy that also guarantees the survival of the vernaculars as instructional languages. In this way, through the bilingual education policy Pakistan will flourish in all aspects of social life.

Moreover, the participant (16) critically sees the prospects of the dynamic, bilingual education in the devolution of authority:

"It is fault of the country's political system and the only prospect of the dynamic, bilingual education in Pakistan is to bring some changes in the system. It can be done by giving full autonomy to provinces in which the federal should only circumscribe its role to foreign policies and promoting Urdu as it is a symbol of unity. Provinces will then exercise their power to bring forth the dynamic, bilingual education along with many other positive changes" (Participant 16).

He says that the country's highly centralized system is not compactable with its multi-lingual reality. He calls the system much flawed especially when it comes to language policy making process. He, therefore, suggests some changes to be made in the system. He asks the concerned authorities to devolve power to the provinces. Although the federal government may impose pro-Urdu policy, the provinces must make sure to introduce the dynamic, bilingual medium of instruction to raise the educational standards of the concerned students. He is quite hopeful that the bilingual education policies will enhance societal cohesion between the federal and provinces, and bring forth transcultural interaction, multilingual repertoire and functional biliteracy/multiliteracy in Pakistan's students. Thus, the dynamic, bilingual education 
policy will indeed solve the country's so far unaddressed linguistic, educational, and social problems.

\section{Discussion}

There are both hopes and challenges to the dynamic model of education in Pakistan. Language policy-makers even in the proposed Single Uniform Curriculum (2020) have suppressed any hope of the dynamic model of education. Moreover, the lack of training and relevant material are challenges to the concerned mode of education, however, there is will among some teachers to employ the mode of instruction. In contrast, there are also hopes for the dynamic model of bilingual education. Since Pakistan is a country of multilingual reality, there are demands from different ethnic groups for their language rights. People are also engaged in language activism for linguistic justice. Furthermore, this research paper draws its inspiration from Garcia's book (2009 pg. 180-181) in which she has highlighted socio-cognitive, linguistic advantages of dynamic, bilingual education around the world. Similarly, this mode of bilingual education can resolve language issues in Pakistan by mainstreaming the local languages into educational curriculum and institutions.

\section{Conclusion}

Finally, the current research paper comes up with a suggestion of bottom-up approach in making the dynamic, bilingual education policy. The analysis of primary data clearly reveals that the dynamic, bilingual education improves sociocognitive, linguistic performance and functional biliteracy of students. Moreover, it also possesses potential of solving Pakistan's language problems as it has solved the language problems of other countries. Although there are challenges to the dynamic, bilingual education, but there are promising prospects as well that will ensure the imposition of the known bilingual instruction policy in Pakistan. Besides, the researcher collected data from some language experts through survey questionnaires and thereby contributed primary, new data to the field of bilingual education and policy planning. The current research is important as it will enable policymakers to realize the benefits offered by the dynamic, bilingual education policy and thus, they will work to impose it in Pakistan. Similarly, the research will also pave the way for applied linguists to do further investigation in the arena of the bilingual education by using different research designs.

\section{References}

[1]. Channa, Khalid H., and Shumaila Memon. "MEDIUM OF INSTRUCTION AND BILINGUAL EDUCATION: A STUDY OF CHALLENGES AND OPPORTUNITIES."
Academia.edu - Share Research, Grassroots, 2016, www.academia.edu/29159711/MEDIUM_OF_INS TRUCTION_AND_BILINGUAL_EDUCATION_ A_STUDY_OF_CHALLENGES_AND_OPPORT UNITIES.

[2]. Federal Ministry of Education and Professional Training. "National Education Policy 2009." Idarae-Taleem-o-Aagahi | Education | Education in Pakistan | Equity | Inclusion, Government of Pakistan, 2009 , itacec.org/document/2015/7/National_Education_P olicy_2009.pdf.

[3]. García, Ofelia. Bilingual Education in the 21st Century: A Global Perspective. John Wiley \& Sons, 2011

[4]. Gulzar, Malik A. "classroom discourse in bilingual context: effects of code switching on language learning in Pakistan tefl classroom." Welcome to Pakistan Research Repository, Higher Education Commission, 2010 , prr.hec.gov.pk/jspui/bitstream/123456789/1865/1/1 385S.pdf.

[5]. Habib, Masooma. "Education in Pakistan's Punjab: Outcomes and Interventions." THE LAHORE JOURNAL OF ECONOMICS, vol. 18, no. Special Edition, 2013, pp. 21-48.

[6]. Hassan, R. "A Comparative Study of the Pakistani Bilingual and Monoglot School Children's Performance in Verbal and Non-verbal Test." Pakistan Journal of Psychology, vol. 3, 1981.

[7]. Jabeen, S. "Google Scholar." Google Scholar, 2010 ,

scholar.google.com/scholar_lookup?title=Research $\% 20$ in $\% 20$ bilingualism $\% 3 \mathrm{~A} \% 20 \mathrm{~A} \% 20$ dilemma $\%$ 21\&author=S.\%20Jabeen\&journal=Explorations\& volume $=21 \&$ pages $=67$ -

79\&publication_year $=2010$.

[8]. Jain, Rashi, and Ahmar Mahboob. "Bilingual Education in Pakistan and India." Academia.edu Share Research, 2014, www.academia.edu/19613397/Bilingual_Educatio n_in_Pakistan_and_Indiahttps://www.academia.ed u/19613397/Bilingual_Education_in_Pakistan_and _India.

[9]. Lewis, M. P. Ethnologue: Languages of the World. 19th ed., International Academic Bookstore, 2016. 
[10]. Mahon, Merle, Alison Crutchley and Tina Quinn. "Editorial: New directions in the assessment of bilingual children." https://faculty.biu.ac.il/ armonls/924/NWR/assess ment\%20of\%20bilingual\%20children.pdf Arnold, 2003 ,

faculty.biu.ac.il/ armonls/924/NWR/assessment\% 20of\%20bilingual\%20children.pdf.

[11]. Manan, Syed A., Maya Khemlani David and Francisco Dumanig. "English Language Teaching in Pakistan: Language Policies, Delusions and Solutions." Language Policy, 2016, pp. 219-244.

[12]. Ministry of Federal Education and Professional Training. "Ministry of Federal Education and Professional Training." Ministry of Federal Education and Professional Training, Government of Pakistan, 2020, mofept.gov.pk/Detail/NWJmMmM2YTQtM2YzYi 00NjJkLTgzNDEtYzMxMTI4MTIlY2Qw.

[13]. García, Ofelia. Bilingual Education in the 21st Century: A Global Perspective. John Wiley \& Sons, 2009, pp. 180-181 (mobile version).

[14]. Qadir, M. A. "Issues of language(s) choice and use: a Pakistani perspective." CiteSeerX, Pakistan Journal of Social Sciences, 2010, citeseerx.ist.psu.edu/viewdoc/download?doi=10.1. $1.700 .7427 \&$ rep=rep1\&type $=$ pdf.

[15]. Quad, A. "Research Methodology in Education: Ethnography - Research Methodology in Education." Research Methodology in Education An LLED 2016 , lled500.trubox.ca/2016/207.

[16]. Rahman, Tariq. "Denizens of alien worlds: A survey of students and teachers at Pakistan's Urdu and English language-medium schools, andmadrassas." Contemporary South Asia, vol. 13, no. 3 , 2004, pp. 307-326.

[17]. "Raja, F. U. (2014). Bilingual Education System at Primary Levels of Pakistan. Journal of Research (humanities), 77-99

[18]. Sunaina, A. "Bilingual Curricula for Equity Literacy in Punjab, Pakistan." Cardinal Scholar Home, Ball State University, 2019, cardinalscholar.bsu.edu/handle/123456789/201629. Accessed 14 Sept. 2020.

[19]. Tariq, A. R., and H. A. Bilal. "Functions of codeswitching in Bilingual classrooms." Research on
Humanities and Social Sciences, vol. 3, no. 14, 2013, pp. 29-34.

[20]. UNESCO. "2016." UNESCO | Building Peace in the Minds of Men and Women, 2016, en.unesco.org/gem-report/taxonomy/term/198. 